\title{
Escribir contra el discurso hegemónico, de la teoría a la acción: No tan incendiario y la narrativa de Marta Sanz
}

Sánchez Zapatero, Javier

Universidad de Salamanca, España

zapa@usal.es

Reyes Martín, Raquel

Universidad de Salamanca, España

raquel37900@usal.es

Cita sugerida: Sánchez Zapatero, J. y Reyes Martín, R.(2018).Escribir contra el discurso hegemónico, de la teoría a la acción: No tan incendiario y la narrativa de Marta Sanz. En C. Somolinos Molina (ed.) "Escrituras del cuerpo: Marta Sanz". Olivar, 18 (27), e022. https://doi.org/10.24215/18524478e022 


\section{Escribir contra el discurso hegemónico, de la teoría a la acción: No tan incendiario y la narrativa de Marta Sanz}

Write against the hegemonic discourse, from theory to action: No tan incendiario and the Marta Sanz Narrative

Javier Sánchez Zapatero

Universidad de Salamanca, España

zapa@usal.es

Raquel Reyes Martin

Universidad de Salamanca, España

raquel37900@usal.es

\section{Resumen:}

A través del análisis del ensayo No tan incendiario (2014) y de algunas de sus principales novelas - Animales domésticos (2003), Black, black, black (2010), Un buen detective no se casa jamás (2012), Daniela Astor y la caja negra (2013) y Farándula (2015)-, el artículo expone algunas de las características de la literatura de Marta Sanz, referidas, fundamentalmente, a la forma en la que a través de ella se canaliza una actitud comprometida y crítica que intenta oponerse a los discursos dominantes que emanan desde los focos de poder.

Palabras clave: Marta Sanz, Compromiso, No tan incendiario, Literatura Española Contemporánea, Novela Española Contemporánea.

\section{Abstract:}

The article takes as its point of reference some Marta Sanz's works -the essay No tan incendario (2014) and some of her novels: Animales domésticos (2003), Black, black, black (2010), Un buen detective no se casa jamás (2012), Daniela Astor y la caja negra (2013) y Farándula (2015) - in order to study the fundamental characteristics of her literatura and, specially, the importance of the commitment, of the fight against hegemonic thinking and of the critical attitude.

KEYWORDS: Marta Sanz, Commitment, No tan incendario, Contemporary Spanish Literature, Contemporary Spanish Novel.

Autora de una heterogénea obra que incluye narrativa, poesía, ensayo y crítica literaria, Marta Sanz publicó en 2014 No tan incendiario. Presentado con el subtítulo de "Textos políticos que salen del cenáculo" y con una estructura de collage que permite que diversas reflexiones tomadas en ocasiones de conferencias y artículos periodísticos se vayan engarzando a lo largo de siete capítulos de diferentes extensiones y formatos, el texto cuestiona el papel de la literatura y de los escritores en el actual y convulso contexto social, político y cultural. Partiendo de la base de que toda literatura es política, incluso -o, más bien, sobre todo- aquella que voluntariamente no se presenta como tal, la autora reclama una intervención abierta y consciente del escritor en los asuntos públicos a través de su obra. No en vano, en el prólogo de la obra se afirma que esta nace de la "imposibilidad de estar conforme" (2014, p. 8). Quizá por eso pueda detectarse a través de su lectura una voluntad apelativa al mismo tiempo que catártica que lleva a Sanz a llamar la atención del lector, obligándole a no mostrarse indiferente ante los intentos narcotizadores que sobre la sociedad parecen ejercer los poderes políticos y empresariales -empeñados en potenciar un arte aparentemente desideologizado que no lo es en absoluto-, y, simultáneamente, a reflexionar sobre la literatura, que también es en cierto modo una forma de reflexionar sobre sí misma. Y es que No tan incendiario admite una lectura personal, por cuanto arroja una serie de claves de la poética de la autora que permiten interpretar su obra literaria desde la posición activa y conscientemente contestataria contra lo establecido que reclama para las creaciones artísticas contemporáneas. En consecuencia, las siguientes páginas tratarán de hacer dialogar algunos hitos de su narrativa -Animales domésticos (2003), Black, black, black (2010), Un buen detective no se casa jamás 
(2012), Daniela Astor y la caja negra (2013) y Farándula (2015) - con las aportaciones del ensayo, mostrando así la coherencia programática que destila su trayectoria literaria, en la que ética y estética parecen fundirse.

\section{Frente AL IMPERATIVo (DEL ÉXITO) INDIVIDUAL: ANIMALES DoméSTICOS}

En diversos fragmentos de No tan incendiario se reivindica la necesidad de conectar la literatura con su contexto circundante, como cuando se afirma que "es necesario contar historias y volver, en definitiva, a la literatura como forma de conciencia de la vida y como capacidad de nombrar y de intervenir en el mundo" (2014, p. 148); cuando se aboga por "una reivindicación del discurso abiertamente político [...] [y por] una declaración contra la (aparente) neutralidad, contra lo inofensivo y lo intrascendente" (2014, p. 124); o cuando se señala que "toda la cultura encarna un posicionamiento ideológico" (2014, p. 24). Más allá de la evocación al compromiso sartriano y de la asunción de que "todo escrito posee un sentido" (Sartre, 2003, p. 11), bajo estas palabras parecen subyacer las conclusiones de algunos de los referentes del pensamiento contemporáneo como Pierre Bourdieu o Slavoj Žižek, a quienes, no por casualidad, se cita explícitamente en el texto. Ambos comparten con la autora una concepción del arte que trasciende lo meramente estético y que, enmarcándose dentro del giro pragmático que ha marcado el desarrollo de la teoría cultural de la segunda mitad del siglo XX, considera que el discurso literario ha de ser analizado teniendo en cuenta, además de su condición textual, su dimensión pragmática. Como práctica social, la literatura está enraizada en algunas de las ideas manejadas por ambos autores que, de uno u otro modo, aparecen en No tan incendiario. En el caso de Bourdieu, además del vaciamiento del valor que implica su concepción del "capital simbólico" (1995), que otorga a la dinámica de las relaciones establecidas en el contexto social la capacidad axiológica de juzgar una obra, resulta sumamente interesante comprobar cómo su teoría de la "violencia simbólica" dialoga con el ensayo, y con la poética, de Sanz. Para el autor francés, existe en las sociedades una "violencia que arranca sumisiones que ni siquiera se perciben como tales apoyándose en una expectativas colectivas, en unas creencias socialmente inculcadas" (1999, p. 172) y que, en consecuencia, convierte en aparente acuerdo lo que no es más que imposición. Evidentemente, la literatura no es ajena a la estructura de dominación que implica esta violencia soterrada e invisible, puesto que en su representación del imaginario colectivo puede reproducir una serie de estructuras destinadas a perpetuar las estructuras de poder, configurando un imaginario monolítico y férreo en el que no caben alternativas, y consolidando una serie de valores vinculados con los objetivos de quienes ocupan una posición hegemónica. Algo similar concluyen las teorías de Slavoj Žižek que, en Sobre la violencia: seis reflexiones marginales (2008), planteaba, grosso modo, la necesidad de asumir que una de las múltiples formas a través de las que la violencia sistémica se presenta en las sociedades democráticas y capitalistas es aquella que se encarna "en el lenguaje y sus formas" (Žižek, 2009, p. 85).

Uno de los fundamentos de este discurso hegemónico e invisible que más se cuestiona en la obra narrativa de Sanz es el referido a la responsabilidad de los individuos en el devenir de su fortuna y de sus pesares sin tener en cuenta el contexto social en el que viven, explícitamente denunciado en No tan incendiario al referirse a sus impulsores como "seres arcangélicos que venden miles de libros en los que gorjean de cómo la tristeza sólo llama a la tristeza igual que la riqueza llama a la riqueza y de cómo somos responsables de nuestra angustia, ansiedad e insomnio" (2014, p. 71). El imperativo del éxito como único modelo de vida a seguir se inscribe dentro de la lógica discursiva impuesta por el capitalismo, algo que Animales domésticos evidencia con una serie de personajes que se mueven "en un entorno hostil, un medio ambiguo y engañoso que, si en apariencia constituye un espacio de múltiples posibilidades, está plagado de obstáculos y trampas que, para ciertos personajes, se revelan como insalvables" (Simó, 2014, p. 39). A través de la historia de un microcosmos familiar, y de las relaciones personales y profesionales que van desarrollando cada uno de sus miembros, la obra muestra cómo la violencia del sistema va penetrando en las entretelas de la esfera privada de los individuos, hasta el punto de condicionar su comportamiento y su visión del mundo. Tal y como ha explicado acertadamente Marta Simó (2014), la novela cobra una dimensión simbólica que la 
lleva a trascender la peripecia de sus personajes y expresar un diagnóstico sobre la realidad histórica. Así, actitudes como las de Elías -que se considera inútil y fuera de la sociedad por no tener trabajo, y se verá obligado, guiado por el mantra del discurso dominante, a intentar convertirse en un empresario "dueño de su destino"-, Esteban -obrero sin condición de clase que trata con condescendencia a sus compañeros y llega a convertirse en esquirol cuando estos plantean actos reivindicativos-, Jarauta -trabajador de baja cualificación, absolutamente condicionado por haber nacido en un entorno casi marginal, que muere en una accidente laboral por culpa de la negligencia de sus superiores-o Marcela -paradigmático ejemplo de mujer sumisa que decide dedicar toda su vida al cuidado del hogar- ponen de manifiesto algunas de las estructuras de dominación propias del capitalismo avanzado. Presente de forma silente en la sociedad, esta violencia sistémica somete a los individuos y los convierte en meros guiñapos a merced de las decisiones del contexto económico y social que, paradójicamente, transmite la falsa y esperanzadora idea de que uno es aquello que se propone ser. La culpabilidad de Elías ante su precaria situación, la incapacidad de Esteban para admitir lo que realmente es, la imposibilidad de Jarauta de escapar del determinismo de sus orígenes o la errónea concepción de sí misma de Marcela son, en consecuencia, pequeños ejemplos cotidianos que denuncian un proceso de dominación también expuesto de forma sintomática y explícita en el título y en alguno de los diálogos de la novela, como aquel en el que un personaje afirma percatarse de "cómo los seres humanos pueden dejar de serlo, poco a poco, a través de una penosa transición que los va consumiendo hasta convertirlos en algo parecido a un animalito" (Sanz, 2003, p. 73). En definitiva, la novela transmite, en la línea de lo apuntado en Señales de humo (2016) de Rafael Reig, la idea de que "el combate se libra en el campo de batalla de las representaciones imaginativas: quiénes creemos que somos, cómo nos contamos a nosotros mismos quiénes somos y lo que nos sucede, qué imaginamos que nos está pasando” (2016, p. 49).

Escrita a comienzos del siglo XXI, en unos años de bonanza económica, Animales domésticos podría haberse escrito perfectamente en nuestro presente de crisis, pues las características que describe y en las que se sitúa no solo no han caducado, sino que se han extendido y agrandado con la actual coyuntura. De hecho, quizá gran parte de la fuerza de su mensaje resida en el hecho de haber sido capaz de detectar el impacto en la sociedad de ciertos comportamientos en un momento en el que sus efectos no eran tan visibles, a modo de trágica e irónica advertencia destinada a no confiar en la prosperidad y la fe en el crecimiento ilimitado. De este modo, la novela confirma que, para Marta Sanz, la literatura ha de "iluminar facetas de la realidad desapercibidas, abordándolas intrépidamente” (apud Labari, 2003), poniendo así ante el lector aquello que no quiere o no está acostumbrado a ver y descubriendo las taras del sistema.

\section{Destapar lo oculto: Daniela Astor y la caja negra}

El valor pragmático que subyace a la concepción literaria de la autora traslada la idea de que no hay literatura inocente, puesto que, como se afirma en No tan incendiario, "las formas culturales con apariencia de neutralidad [...] son las que entrañan mayor peligro", ya que toda cultura, independientemente de sus características, "deja un poso que nos mueve a unos procedimientos determinados de acción o de inacción” (2014, p. 30). Sanz, de hecho, se ha mostrado tremendamente crítica -incluso autocrítica- con la actitud de aquellos escritores que han consolidado con su obra los esquemas de dominación y adocenamiento que implica la violencia simbólica, citando de forma expresa a su generación y a la inmediata precedente, desarrollada en la década de 1980:

Fuimos detrás de los de la Nueva Narrativa, que ocupaban todos los espacios: el prestigio, la prensa. E hicimos poco por construirnos contra ellos. Asumimos de una manera acrítica su visión de la literatura: el entretenimiento, la prevalencia de las tramas, eso que se llama escribir bien y que, con el tiempo, hemos visto que significa estar conforme. Esos escritores dibujaban una visión de España muy estupenda, la España de la democracia, el postfranquismo, la España de las libertades, de las burbujas, de las novelas protagonizadas por escritores, por cantantes de ópera... (apud Gordo, 2015) 
En términos similares se ha expresado David Becerra, para quien Sanz supone, junto a otros autores como Belén Gopegui, Rafael Reig, Rafael Chirbes o Isaac Rosa, una excepción en un panorama literario dominado por la "novela aideológica", aquella que "reproduce la ideología dominante del capitalismo avanzado: que vivimos en el mejor de los mundos posibles, un mundo perfecto y acabado, sin conflictos, en el que no pasa nada, o donde lo único que pasa se localiza en el interior, en el yo" (2013, p. 44). Este tipo de literatura coincide con la desarrollada por aquellos a quienes Vázquez Montalbán denominó “escribas sentados”, categoría que representaría de forma sintomática al "intelectual mero avalador directo o indirecto de la ideología dominante (...), reproductor de ideas al que las palabras no le pertenecen” (1997, p. 14-15). Frente a esta forma de hacer literatura, que naturaliza la violencia invisible del sistema y silencia cualquier alusión a la conflictividad social o la reflexión política, Marta Sanz propone una actitud responsable que lleve al escritor a cuestionar el orden establecido, convirtiéndose así en un "escriba no sentado o disidente" que, consciente de las implicaciones de su actividad, sea capaz de visibilizar tanto esa presión soterrada que condiciona las dinámicas sociales como las carencias de un sistema que ha ido silenciando cualquier muestra de disidencia. En consecuencia, en palabras de Sánchez Dueñas,

sus creaciones se originan y parten desde el presente, de la realidad inconfesada o desatendida que nos rodea para ofrecerla con toda su crudeza, su paroxismo, sus obsesiones y su calado, [...], mostrando las realidades que nos rodean, aunque no las queramos ver o aunque tratemos de desviar nuestras miradas hacia otro lado. (2012, p. 628)

Así sucede, por ejemplo, en Daniela Astor y la caja negra, que, más allá de revisar el triunfalista discurso impuesto desde el poder sobre el proceso reformista de la Transición -lo que la emparenta con narraciones contemporáneas como las de Antonio Orejudo o Rafael Reig- y poner de manifiesto algunas de sus principales taras, denuncia cómo bajo la aparente liberación de la mujer en los años del final de la década de 1970 y del comienzo de la de 1980 en la sociedad española subyacía un tipo diferente de dominación. En el fondo, lo que muestra la obra a través de la historia de Catalina y Angélica, dos niñas de la España de 1978 que tienen como ídolos a las por entonces tan populares actrices del "cine de destape", habituales reclamos en las portadas de las revistas del corazón de la época, es el proceso por el que se perpetúan los esquemas de dominación patriarcal en la representación cultural de la mujer, transformando lo que antaño era un rol pasivo, de cuidado del hogar y sostén de la familia, a otro que la reduce a la mera corporeidad y la convierte en mero objeto de deseo, tal y como se puede leer en la novela:

El desnudo se transforma en destape cuando se vacía de sentido y oportunidad, y sobre todo cuando se enfoca en primer plano la mirada del macho y el movimiento: la represión sexual, el morderse los labios y sacar los ojos de las órbitas ante la contemplación del cuerpo de la mujer. (2013, p. 139).

Semejante proceso de cosificación trasciende el mero contenido de las películas de destape o fantaterror, e incluso las fotografías de chicas desnudas y en actitud seductora de muchas publicaciones de aquel periodo, y termina por influir en la configuración de los estereotipos y la posición de la mujer en el imaginario colectivo, evidenciando con ello el valor de correas de transmisión del pensamiento hegemónico de las representaciones culturales. A ese respecto, no solo es importante hacer hincapié en el hecho de que Catalina y Angélica sueñen con ser como esas actrices a las que admiran -y que en nada se parecen a los modelos de mujer que representan, por ejemplo, sus madres, profesionales independientes que trabajan fuera de casa-, sino también en la forma en que su visión de la realidad acaba siendo influida por aquello que ven en los medios de comunicación y las producciones artísticas, tal y como pone de manifiesto Catalina en algunos momentos de la narración:

Mi madre parece tan injusta que llego a desear que mi padre le dé un bofetón para callarle la boca. Lo he visto en tantas películas. Las nalgas azotadas y la cara cruzada en el acto justiciero de quien tiene la razón y la vara de medir. (2013, p. 130).

La misma cosmovisión machista se observa cuando la protagonista repite sin cuestionar la opinión del padre de su amiga Angélica de que "para ser buena actriz es mejor ser una estúpida. Dejarse moldear por un buen director. Ser esculpida en piedra. No preguntarse casi nada” (2013: 50). Asimismo, la presión patriarcal 
es perceptible en la obra cuando se aborda el tema del aborto y se muestra cómo la estigmatización que sufren las mujeres que quieren llevarlo a cabo funciona en tres niveles diferentes: el público, por el que se les demoniza socialmente e incluso se les condena judicialmente; el cultural, que presenta la cuestión "desde la sordidez y la parafernalia de la hechicería" (2013, p. 169-170); y el privado, que provoca en la intimidad familiar quien decide no tener un hijo sea tildada por su pareja de "irracional", "cruel", "egoísta", "inculta", "desagradecida" y "completamente loca" (2013, p. 160).

Gracias a la construcción de la novela, en la que se combinan el relato rememorador de Catalina con los documentos referenciales que utiliza desde el presente para llevar a cabo un documental sobre los iconos femeninos de aquella época, Daniela Astor y la caja negra no limita su valor contestatario a la construcción del relato de la Transición, fijándose también en lo que sucede en la actualidad. Es decir, tal y como ha afirmado Cristina Somolinos, la dualidad de planos temporales demuestra que "la Catalina de cincuenta años no ha escapado a esas opresiones que de pequeña no sabía cómo interpretar, sino que se enfrenta a ellas desde otra óptica que la progresiva toma de conciencia le ha otorgado" (2015, p. 102). Por tanto, se puede ver el desarrollo sufrido por una preadolescente cuya visión de la realidad evoluciona abruptamente de ingenua a dramática al tener que abandonar sus juegos infantiles para tomar conciencia de quién y qué tipo de mujer quiere ser -pasando así de objeto pasivo a sujeto activo-, sino también y sobre todo qué ha quedado de aquel imaginario. No es anecdótico, por tanto, que a lo largo de la novela se repitan de forma recurrente los nombres de algunas de las actrices que fueron elevadas a la categoría de mito erótico en la época, condenadas en muchos casos en la actualidad al olvido más absoluto e incluso convertidas en "juguetes rotos" que después de coquetear con el éxito y la popularidad han terminado, como en el caso de Nadiuska, malviviendo en la calle; ni tampoco que se mencione cómo el cuerpo femenino sigue en la actualidad sometido a un proceso cosificador marcado por el consumo de pornografía y la homogeneización de un determinado canon de belleza; ni que, en el último capítulo de la obra, se aluda a formatos de televisión de la actualidad que reproducen estereotipos, comportamientos e iconos culturales análogos a los de hace treinta años. Lejos de ser baladí, esa referencia está en plena consonancia con una de las ideas aportadas por la autora en No tan incendiario, donde, consciente de las posibilidades de los medios de comunicación de masas para transmitir una imagen determinada de la realidad y de la redefinición que está sufriendo el término "alienación” en la actualidad, se sostiene que es "necesario tener una televisión en casa" y "saber lo que está pasando alrededor (...), no la verdad de las noticias, sino el pulso del país” (2014, p. 52), alejándose así de forma voluntaria de esos intelectuales ensimismados encerrados en sí mismos, en su obra y en su torre de marfil.

La capacidad de las imágenes y los mensajes de los artefactos culturales de representación para determinar el imaginario está también presente en Éramos mujeres jóvenes (2016), libro que complementa y dialoga con Daniela Astor y la caja negra, tal y como demuestra su subtítulo: Una educación sentimental de la transición española. En este híbrido entre el ensayo personal, la crónica social y la memoria, Sanz analiza -con ayuda de los testimonios de sus "corifeas": amigas nacidas en las décadas de 1950 y 1960 que han aceptado realizar un cuestionario respecto a su intimidad y sus "usos amorosos", término con el que se explicita la clara conexión de la obra con los ensayos de Carmen Martín Gaite sobre el siglo XVIII y la posguerra españoles- cómo la sentimentalidad de las mujeres que alcanzaron su madurez en la Transición y de las representantes de generaciones más recientes ha sido configurada a través de una serie de imaginarios muy concretos difundidos a través de discursos publicitarios, mediáticos y ficcionales. Así, explicita cómo "lo externo se nos mete dentro y lo interno a veces se regurgita fuera, y esas regurgitaciones -artísticas, culturales, de andar por casa- regresan al territorio interior de los individuos" (2016, p. 133) hasta el punto de provocar que "lo biológico y lo histórico se entrelazaron para hacer coincidir nuestro despertar sexual y nuestra pubertad con la adolescencia de un país que también estaba lleno de miedo y esperanza" (2016, p. 134). El ensayo también otorga importancia a la figura de la mujer como escritora, y no solo como lectora, al aludir a la proliferación de autoras de las últimas décadas que no solo han aportado un nuevo punto de vista y una configuración 
autónoma de su propia identidad alejada del estereotipo, sino también un cambio estilístico y formal, algo que se puede comprobar en la escritura de Marta Sanz, "permanentemente contra lo cursi" (2016, p. 138).

\section{La literatura del Caballo de Troya: las novelas de Arturo Zarco}

Tal y como se puede observar en Daniela Astory la caja negra y su intento de relatar aquello que habitualmente no se cuenta, la propuesta narrativa de Marta Sanz está muy relacionada con la propugnada por Belén Gopegui, quien en Un pistoletazo en medio de un concierto (2008) sostiene que la verosimilitud ha dejado de ser un concepto estético para dotarse de una dimensión política, por cuanto se le imponen unos límites y se le hace tener correspondencia con una realidad muy concreta de la que resulta imposible substraerse. Según Gopegui, resulta imposible en la actualidad "escribir acerca de individuos que pretenden instaurar un nuevo sistema sin tratarles de totalitarios, enfermos, ingenuos" (2008, p. 18), puesto que el pensamiento hegemónico parece haber instaurado con fuerza la idea de la imperturbabilidad -y, por extensión, de la eficacia- del sistema y, al mismo tiempo, el carácter quijotesco de cualquier idealista que pretende modificarlo. De ahí que escribir intentando huir de esa verosimilitud impuesta implique poner en práctica esa actitud contestataria y visibilizadora reclamada por Sanz, algo complicado en un contexto en el que la literatura se ha convertido en un bien de mercado, lo que no solo ha conllevado que "se legitime como cultura lo que se publicita como tal" (2014, p. 61), sino también y sobre todo que los autores estén sometidos a una serie de condicionamientos entre los que lo meramente artístico parece sometido a lo económico, lo político o lo empresarial:

\footnotetext{
Vivimos en una sociedad de mercado, y hay gente que no, que no es honesta o gente que se autocensura o gente que escribe lo que cree que debe escribir para vender muchos libros y complacer a muchos lectores. (...) Por miedo, es una forma de miedo económico. A veces se formula de forma consciente y la mayoría de las veces es una presión que interiorizamos sin hacernos preguntas. Es un poco como la pescadilla que se muerde la cola. Si yo como escritora no te complazco a ti, lectora, y a muchísimos más, eso significa que a lo mejor yo no voy a vender muchos libros y, si no vendo muchos libros, se me cierra la puerta de las editoriales y, si se me cierra la puerta de las editoriales, al final la escritura se convierte en un acto onanista y autosatisfecho, donde no se cumple el proceso comunicativo que culmina cuando yo soy capaz de trasladarte a ti, receptor, mis inquietudes, mis incertidumbres, mis experiencias, mis emociones, mi visión del mundo, mi ideología. (apud Bonet y Fernández Recuero, 2016)
}

Las presiones a las que alude la cita han sido sufridas por la propia autora, que hubo de esperar más de diez años a que su novela Amor Fou (2014) fuese publicada, después de haber sido sucesivamente comprada y rechazada por dos editoriales. Ante semejante coyuntura, que pone de manifiesto cuál es el sustantivo y cuál el adjetivo cuando se habla de "industria cultural", la autora ha propuesto, junto a otros autores en el proyecto colectivo Qué hacemos con la literatura (2013), la teoría del “caballo de Troya”, basada en la idea de que, en lugar de constituir una alternativa al margen de lo establecido, hay que utilizar los medios del sistema dominante para intentar subvertirlo:

El caballo tiene que tener forma de caballo. Pero no sólo para cruzar las murallas de la ciudad enemiga, sino también para que el discurso subversivo pueda llegar con mayor facilidad a sus lectores potenciales. Si la literatura subversiva adquiere la apariencia del best-seller, sus posibilidades revolucionarias pueden llegar a multiplicarse, en la medida que alcanzan a un mayor número de lectores. (Arias, Rodríguez Puértolas, Sanz y Becerra, 2013, p. 47)

La imagen del "caballo de Troya" resulta sumamente clarificadora para entender la situación de Marta Sanz en el campo literario español, en el que ocupa una posición de referencia gracias a la inclusión de sus obras en los catálogos de editoriales como Destino y Anagrama, a la concesión de galardones como el Premio Herralde de Novela o a la atención que sus obras acostumbran a recibir por parte del público y la crítica especializada. Lejos de interpretarse como una contradicción en alguien que propugna una literatura subversiva, semejante postura subraya de forma evidente el interés de la autora, en su intención de dotar a su obra de una dimensión pragmática a través de la que intervenir en asuntos públicos y cuestionar determinados aspectos de la realidad, 
de llegar al mayor número de lectores posibles en las mejores circunstancias posibles. Como la propia escritora ha confesado en una entrevista, no parece haber otra alternativa que aprovechar los resquicios del sistema para poder señalar sus taras, pues escribir y publicar al margen de los canales convencionales no es opción viable para alguien que aspira a transformar el mundo a través de la literatura: “¿Qué hago yo? ¿Me pongo a autoeditarme? ¿Me abro un blog? ¿Olvido toda mi trayectoria literaria y me pongo a tocar el tamtam en la calle a ver si llego por señas a más gente?” (apud Bonet y Fernández Recuero, 2016).

Probablemente las dos novelas de su producción que de forma más paradigmática ponen de manifiesto esta necesidad de conciliar la adecuación a las pautas del campo literario con una concepción literaria abiertamente disidente tanto en la forma como en el contenido sean Black, black, black y Un buen detective no se casa jamás, componentes de la serie narrativa protagonizada por el investigador privado Arturo Zarco. Ambas fueron publicadas en los años de mayor esplendor comercial del género policiaco en España, coincidente con fenómenos, aún vigentes, como la traducción masiva de numerosas novelas procedentes de otras literaturas -y, especialmente, y aprovechando el tirón comercial de la saga Millenium (2005-2007), de Escandinavia-, con la celebración de festivales vinculados a la novela negra en prácticamente toda la geografía nacional y con la inclusión de títulos análogos en casi todas las editoriales, que en muchos casos llegaron a crear colecciones especializadas. Sin embargo, su inmersión en ese contexto no implicó el seguidismo a los cánones del género, sino su continua alteración a través de diversos procedimientos, desde la configuración del personaje principal -antítesis de los estereotipos detectivescos instalados en el imaginario colectivo por su homosexualidad, lo rutinario de su actividad o la dificultad con la que avanza en los casos en los que trabajahasta la construcción de las tramas argumentales que, o bien no terminan con la clausura del caso investigado, sino, más bien, con la constatación de que es impensable que la verdad de un caso criminal salga a la luz porque hay tantas verdades como implicados en él -como ocurre en la primera novela-, o bien se inician en un momento de asueto del investigador, en uno de esos "tiempos muertos" que habitualmente no se reflejan en la literatura -como en la segunda-. No en vano, Ricardo Senabre se refirió a Black, black, black como "una falsa novela negra", puesto que en ella "la intriga que se trata de aclarar es una pura creación literaria (...), porque lo que se plantea de verdad es el problema de las relaciones entre realidad y ficción” (2010). En semejantes términos se expresó Miguel Sanfeliú, para quien la obra es, por encima de todo, "una profunda exploración sobre el punto de vista, sobre la distorsión de la realidad" (2010), confirmando con ello la recurrente preocupación de Marta Sanz por el poder del lenguaje de transformar e imponer visiones del mundo.

La capacidad subversiva de las dos novelas implica una posición que trasciende lo meramente estético, puesto que, como la propia autora admite en No tan incendiario, "el éxito de un género viene condicionado por su capacidad para conectar con una gran masa acrítica, para reflejar la ideología invisible” (2014, p. 90) a través de la reiteración de una serie de elementos altamente codificados, ya que, tal y como puso de manifiesto George Orwell, "los tópicos y las frases hechas solo sirven para ahorrarle a la gente el esfuerzo de pensar" (2009, p. 131) y como la propia autora evidenció en su poemario Perra mentirosa (2010): "No quiero la palabra precisa / es pobre y pequeña./ Quiero una palabra / llena de flecos” (2010, p. 37). En el caso de la novela negra contemporánea -y de forma especial de la narrativa serial-, el éxito popular alcanzado en los últimos años ha conllevado la creación de un tipo de público cada vez menos expuesto a la capacidad de extrañamiento de la literatura que basa gran parte de su gratificación lectora en el reconocimiento de tópicos formales y temáticos. De hecho, se ha impuesto como tendencia un tipo de novela determinado, protagonizada por un agente policial que tiene que hacer frente a sus problemas personales al tiempo que desarrolla una investigación, con una clara intención de didactismo costumbrista que lleva a incluir descripciones de referentes geográficos o de muestras de la gastronomía local y que suele finalizar con la resolución de un caso criminal, proyectando así la idea de que las taras del sistema pueden ser detectadas y solucionadas por los mismos que lo representan, o de que los criminales son desequilibrados o asesinos en serie que actúan violentamente "porque están locos y no porque sean ese tipo de víctima del sistema que 
acaba convirtiéndose en verdugo" (Sanz apud Becerra, 2015). Se visibiliza de esta forma que el problema dentro del sistema es un tipo de violencia física que se ejerce desde la enajenación o la psicopatía. En cambio, no se describe el tipo de violencia que el propio sistema proyecta ni se reflexiona sobre las razones que llevan a algunos individuos a comportarse con agresividad. De esta forma, el investigador que en los últimos tiempos se está convirtiendo en estereotipo respalda el pensamiento dominante, pues su comportamiento transmite la idea de que la única anomalía que existe dentro de la sociedad está representada por los individuos problemáticos que no logran adaptarse a ella.

Con algunas excepciones como la de Carlos Zanón o Rafael Reig, este esquema aparece en la obra de gran parte de los autores que han cultivado el género en los últimos años y que, en cierto modo, lo han reducido a un mero armazón esquemático y argumental, en una especie de "National Geographic del crimen” a través del que conocer diversos lugares y formas de vida del país a través del pulular de los personajes investigadores sin plantearse que resolver un crimen es, por encima de todo, plantearse cómo y por qué existe la violencia en la sociedad. En esa literatura biempensante y complaciente no hay vocación de apelar e intranquilizar al lector, algo que difiere sustancialmente con los propios orígenes de la novela negra y que confirma cómo el género ha ido transformándose -y "domesticándose" - a medida que ha ido ocupando un papel central en el campo literario. A principios del siglo, autores estadounidenses como Dashiell Hammett no solo demostraron su capacidad de hacer una literatura estilísticamente diferente, basada en la frase corta, la escritura sobria y la agilidad de acción, sino también su intención de descubrir de forma explícita de qué forma el poder condenaba y acallaba cualquier tipo de disidencia - piénsese, en ese sentido, en cómo el argumento de Cosecha Roja (Red Harvest, 1929) tiene como punto de partida los problemas sociales que genera la decisión de un empresario de contratar a unos matones para sofocar violentamente una huelga de mineros-. Esa literatura que duele, que habla de la realidad, que enseña aquello que no apetece ver y que denuncia cómo hemos asimilado como normal formas de dominación sistémicas -y, al mismo tiempo, cómo hemos reducido la violencia al mero espectáculo, minimizando el poder de la violencia cotidiana, menos efectista que la que muestran las explosiones pero con la misma capacidad perturbadora- es precisamente por la que aboga Sanz, explícitamente expuesta en Black, black, black y en Un buen detective no se casa jamás a través del tratamiento de temas como el maltrato doméstico, la miseria, la soledad o la marginación.

\section{LA BANALIDAD DE LA CULTURA: FARÁNDULA}

No tan incendiario analiza la literatura dentro del sistema cultural y económico contemporáneo, sin olvidar sus relaciones con otros medios ni su progresiva conversión en objeto de consumo y forma de ocio. La autora afirma con vehemencia que la cultura no es, no puede ser, "tan sólo un artefacto lúdico para ocupar momentos de ocio" (2014, p. 19) y que, en consecuencia, la cultura en general -y la literatura en particular- no ha de ser un bálsamo para los problemas contemporáneos, sino, al contrario, una herramienta para ser consciente de que "el mundo ha cambiado, pero no tanto como nos quieren hacer creer; siguen existiendo los ricos y los pobres, los explotados y los explotadores" (2014, p. 179). Con esta reflexión, de hecho, termina el libro, en un capítulo paradigmáticamente titulado "Marx y la literatura" en el que se reacciona con fuerza contra esa literatura conservadora que parece haberse convertido en tendencia en un mundo en el que cada vez se lee más como distracción y menos como forma de obtener un posicionamiento ante los problemas del mundo.

El progresivo proceso de banalización al que han sido sometidos la cultura y el arte es el tema central de Farándula (2015). A partir del relato de la vida de una serie de actores, la novela reflexiona sobre el mundo del espectáculo, incidiendo en cuestiones como la paradoja que supone que un sector instalado en la precariedad, devastado como pocos por los efectos de la crisis, se presente sin embargo rodeado de glamour y luces de neón; la permanente tensión entre el compromiso político y la imagen pública que afecta a aquellos actores que muestran sus ganas de cambiar el mismo sistema del que forman parte; o los cambios que el paso de lo analógico a lo digital está imponiendo en la forma de crear y consumir cultura. Del mismo que en Animales 
domésticos, la estructura coral de la novela permite reflejar las peripecias, continuamente entrecruzadas, de una serie de personajes de valor más alegórico que representativo, aunque exista la tentación de leer la novela en clave y de intentar adivinar qué referentes reales subyacen bajo su configuración: Valeria Falcón -que comienza a ser consciente de la invisibilidad a la que el inminente final de su carrera parece condenarla-, Ana Urrutia -antaño estrella de la interpretación que malvive en la más absoluta de la precariedad-, Natalia de Miguel -cuya trayectoria profesional artística, en la que se combinan trabajos de interpretación con participaciones en reality-shows, está marcada por la búsqueda de notoriedad y reconocimiento público-, Lorenzo Lucas - antiguo galán que intenta continuar con cinismo y ansia de supervivencia en el mundo de la interpretación-, Mariana y Adolfo -actores reivindicativos, que en el pasado lucharon por mejorar las condiciones de trabajo del gremio, y que en la actualidad parecen no encontrar su sitio- o Daniel Valls intérprete de éxito mundial que desea mantener una posición contestataria ante el mismo sistema que le ha encumbrado-. A través de las historias de estos personajes se reflexiona sobre la cada vez mayor incapacidad de la cultura, sometida a un continuo proceso de desideologización y estandarización, para convertirse en portavoz de los problemas del mundo. De este modo, contrapuntea en todo momento algunas de cuestiones que la autora ya se planteaba en las páginas iniciales de No tan incendiario: “¿Tiene la cultura alguna utilidad?, ¿y alguna utilidad específicamente política?, ¿por qué leemos o para qué leemos?” (Sanz, 2014, p. 13).

La visión del mundillo actoral, poliédrico y complejo, es retratado en una novela en la que contenido y forma aparecen estrechamente unidos, hasta el punto de que podría decirse que su propio estilo, hiperbólico y deudor de ciertos recursos como las continuas enumeraciones, impone la imagen que se quiere proyectar sobre el espectáculo. Y es que la mirada de Farándula no es cómoda ni amable, sino desgarradora y patética, provocando que la sonrisa con la que el lector se acerca a ciertos pasajes termine por convertirse en una mueca heladora. Como un esperpento de Valle-Inclán, proyecta sobre el mundo de los actores una lupa deforme, que no solo le permite diseccionar con detalle sus profundidades, sino también y sobre todo exagerar algunas de ellas. En ese sentido, la obra se emparenta con el resto de novelas de la autora y con las opiniones vertidas en la dimensión autopoética que encierra No tan incendiario, puesto que la intención de no hacer una literatura acomodaticia, poniendo en práctica los resortes extrañantes con los que cuenta el lenguaje, está presente en toda la trayectoria narrativa de Sanz. Y es que sus novelas suponen en cierto modo una excepción en la literatura actual al reducir el valor de la trama y centrarse más en cuestiones formales que meramente argumentales. De hecho, difícilmente pueden ser reducidas al resumen de acontecimientos relatados, puesto que, tal y como ha puesto de manifiesto la propia autora, "la trama es un elemento muy secundario dentro de las ficciones o incluso un elemento a batir" y, por tanto, a la hora de contar una historia puede "transmitir una emoción, (...) dar un punto de vista sobre lo que está sucediendo y hablar de las cosas que duelen, sin tener que agarrar[s] e necesariamente al mecanismo de las tramas: interesa más la construcción de los personajes" (apud Bonet y Fernández Recuero, 2016).

Ahora bien, conviene no limitar el valor de Farándula a su reflexión sobre el mundo escénico e interpretarla como una materialización del tópico del theatrum mundi gracias a la que se habla de individuos cosificados y sometidos a las presiones del mundo contemporáneo. En ese sentido, resulta sumamente revelador observar cómo la novela aborda precisamente las consecuencias de presentar bajo el artificio del lenguaje la realidad de un modo diferente y determinado. Así, se expone, por ejemplo, cómo en el imaginario colectivo la representación de los actores sigue estando dominado por tópicos como los de los trajes de etiqueta o la alfombra roja, cuando la profesión ha sido una de las que con más intensidad ha sufrido en los últimos años la precariedad, viéndose obligados muchos de sus miembros a desempeñarse como camareros o dependientes, o a seguir trabajando incluso en los últimos años de su vida por la imposibilidad de cobrar una pensión. La distorsión entre la realidad y la imagen que de ella se quiere dar, presente en toda la obra, parece tener mucho de alegoría del mundo contemporáneo, dominado por la imposición de ese pensamiento positivo que obliga a teñir incluso a la derrota de un tono esperanzador -recuérdese ese mantra de que "la crisis es una oportunidad" o aquel otro de que a la enfermedad se la supera con optimismo, criticados con dureza por la 
autora en diversas entrevistas y manifestaciones públicas- como por el sesgo limitador con el que el mundo digital muestra su visión de la realidad, habitualmente reduccionista y simplificadora.

Del mismo modo, a través del linchamiento mediático que sufre Daniel Valls se muestra cómo conceptos como "compromiso" parecen estar ya solo aceptados si van ligados a formas convencionalizadas como galas benéficas o inanes como intervenciones en redes sociales, con lo que cualquier actuación que intente trascender e ir más allá es rápidamente condenada por la sociedad; o cómo, a pesar de haber asumido que la política ha penetrado de forma sigilosa en nuestra rutina hasta hacerse presente incluso en nuestros gestos más cotidianos, cualquier acción que la explicite parece condenada al rechazo. De esa forma, la novela expone, mediante las peripecias sus personajes las complicaciones de exhibir un pensamiento político en público en la sociedad contemporánea, confirmando así lo que se decía en No tan incendiario acerca de que "el intelectual de prestigio, el intelectual visibilizado, es el intelectual que se ajusta al concepto de 'razón' legitimado desde el sistema: el otro intelectual es a menudo un francotirador, un ciudadano cero, un iluminado" (2013, p. 122).

\section{A MODO DE CONCLUSIÓN: NOVELAS QUE MANCHAN}

La necesidad de revertir el proceso desideologizador sufrido por la cultura y el arte en las últimas décadas, la intención de distanciarse de la literatura propugnada por la industria editorial y los medios de comunicación, y el interés de explicar hasta qué punto el imaginario cultural está mediatizado por la ideología dominante, bases de la poética de Marta Sanz expresada en No tan incendiario, no solo exigen renovar el contenido de sus novelas para hacer visible lo que habitualmente se oculta, sino también aportar nuevas formas narrativas y estilísticas con las que explicar la realidad colectiva. Si, tal y como explicaba Tzvetan Todorov, "el papel reservado a las artes en las sociedades democráticas es (...) el de un laboratorio donde se preparan, en libertad, nuevos mitos de compromiso" (1991, p. 98), su literatura participa de este laboratorio del compromiso y del escepticismo frente a la ideología dominante, señalando las fallas del sistema y la importancia de escribir siendo consciente del momento histórico presente. De la panorámica de su narrativa esbozada en estas páginas se puede deducir, en definitiva, que la autora, mediante sus novelas, trata de explicar que la sumisión al sistema es afianzada gracias a un imaginario cultural dominante cuyo omnímodo poder puede ser visibilizado -y, claro está, cuestionado- mostrando cómo afecta a la vida de los individuos, así como de retratar el pasado inmediato y el presente más actual para poder comprender qué clase de valores se han transmitir y se quieren transmitir a través de la literatura en nuestras sociedades. Frente a esa literatura "cuyas huellas se difuminan, se mimetizan con la atmósfera del discurso del poder” (2014, p. 122), las novelas de Marta Sanz manchan, salpican, dejan una marca indeleble y, al igual que se decía en el aparato paratextual de No tan incendiario, "aspiran a manchar de tinta las manos que las agarren".

\section{Bibliografía}

Arias, R., Rodríguez Puértolas, J., Sanz, M. y Becerra, D. (2013). Qué hacemos con la literatura. Madrid: Akal.

Becerra Mayor, D. (2013). La novela de la no-ideologia. Introducción a la producción literaria del capitalismo avanzado en España. Madrid: Tierra de Nadie.

Becerra Mayor, D. (2015). Entrevista a Marta Sanz: 'El modelo femenino actual es digital, recauchutado, serializado y de pubis infantil. Buensalvaje, 2, 23-25. Recuperado de: http://davidbecerramayor.blogspot.com.es/2015/06 /entrevista-marta-sanz-en-buensalvaje.html

Bonet, P. y Fernández Recuero, A. L. (2016). Marta Sanz: 'Sufrir no nos hace más fuertes, normalmente nos debilita'. Jot Down, marzo. Recuperado de http://www.jotdown.es/2016/03/marta-sanz/

Bourdieu, P. (1995). Las reglas del arte. Génesis y estructura del campo literario. Barcelona: Anagrama.

Bourdieu, P. (1999). Razones prácticas. Sobre una teoría de la acción. Barcelona: Anagrama. 
Gopegui, B. (2008). Un pistoletazo en medio de un concierto: Acerca de escribir de politica en una novela. Madrid: Editorial Complutense.

Gordo, A. (2015). Marta Sanz: 'La opinión descontrolada no es democrática, sino demagógica'. El cultural, 19 de noviembre. Recuperado de: http://www.elcultural.com/noticias/letras/Marta-Sanz-La-opinion-descontroladano-es-democratica-sino-demagogica/8617

Labari, N. (2003). Marta Sanz, en cinco minutos. El mundo, 1 de marzo. Recuperado de: http://www.elmundo.es/el mundolibro/especiales/2003/03/la_novela_que_viene/e_marta.html

Orwell, G. (2006). Orwell periodista. Barcelona: Global Rhythm Press.

Reig, R. (2016). Señales de humo. Barcelona: Tusquets.

Sánchez Dueñas, B. (2012). Relecturas y creación desde la subversión: Susana y los viejos, de Marta Sanz. Signa. Revista de la Asociación Española de Semiótica, 21, 625-649.

Sanfeliu, M. (2010). Black, black, black, Marta Sanz. La tormenta en un vaso. Recuperado de http://latormentaenunv aso.blogspot.com.es/2010/06/black-black-black-marta-sanz.html

Sanz, M. (2003). Animales domésticos. Barcelona: Destino.

Sanz, M. (2010). Black, black, black. Barcelona: Anagrama.

Sanz, M. (2010). Perra mentirosa. Madrid: Bartleby.

Sanz, M. (2012). Un buen detective no se casa jamás. Barcelona: Anagrama.

Sanz, M. (2013). Daniela Astor y la caja negra. Barcelona: Anagrama.

Sanz, M. (2014). No tan incendiario. Cáceres: Periférica.

Sanz, M. (2015). Farándula. Barcelona: Anagrama.

Sanz, M. (2016). Éramos mujeres jóvenes. Una educación sentimental de la transición española. Sevilla: Fundación Lara.

Sartre, J. P. (2003). ¿Qué es la literatura?. Buenos Aires: Losada.

Senabre, R. (2010). Black, black, black. El cultural. 28 de mayo. Recuperado de: http://www.elcultural.com/revista/ letras/Black-black-black/27294

Simó, M. (2014). Ética y estética en la novela realista contemporánea: de Miau (1888) a Animales domésticos (2003). Pasavento: revista de estudios hispánicos, 2(1), 33-56. Recuperado de: http://www.pasavento.com/pdf/n3_sim o_3.pdf

Somolinos Molina, C. (2015). 'Lo personal es político. Patrones de construcción de género en la Transición. Daniela Astor y la caja negra, de Marta Sanz'. Philobiblion: Revista de literaturas hispánica, 2, 91-104. Recuperado de: http://www.joveneshispanistas.com/wp-content/uploads/2016/01/1.07.-Patrones-de-constru cci\%C3\%B3n...-Cristina-Somolinos_AF.pdf.

Todorov, T. (1991). Crítica de la crítica. Barcelona: Paidós.

Vázquez Montalbán, M. (1997). El escriba sentado. Barcelona: Crítica.

Žižek, S. (2009). Sobre la violencia: Seis reflexiones marginales. Barcelona: Paidos Ibérica. 